\title{
"In" or "Out"? An Analysis of the Use of Augmentals in U.S. Presidential Speeches on the Paris Climate Agreement
}

\author{
Stephanie C. Chan ${ }^{1}$ (D) Brian D. Katz ${ }^{1}$ (D) $\cdot$ Daniel Schmidt $^{1} \cdot$ Ruth Anne Rehfeldt $^{1}$
}

Accepted: 12 July 2021 / Published online: 26 November 2021

(C) Crown 2021

\begin{abstract}
Augmentals, as a type of verbal rule, have been used in political speeches either for establishing beneficial cultural values for the populace (Leigland, 2005) or for publicizing political points of view to exert control on public opinion through propaganda (Rakos, 1993). The current study conducted a functional content analysis on two presidential speeches about climate change and global warming regarding whether the United States should enter or exit the Paris Climate Agreement. The purposes of the study were to (a) examine the effects of two types of augmentals (reinforcer-establishing augmentals and punisher-establishing augmentals) on behavior change in the populace, (b) explore the effects of the types of relational frames that formed augmentals, and (c) provide guidance to the public on discriminating propaganda in media sources. The results showed different patterns in the use of augmentals in Donald Trump's speech, which attempted to persuade the populace to support exiting the agreement, compared to Barack Obama's speech, which attempted to persuade the populace to support entering the agreement. Several implications of the study are discussed.
\end{abstract}

Keywords augmental propaganda $\cdot$ relational frame climate change $\cdot$ political speech . Paris Climate Agreement

Political speech, as a persuasive and longstanding political genre, has received profound academic attention that has resulted in the development of various analytic methodologies in linguistic, rhetorical, semiotic, and psychological areas (CharterisBlack, 2014). However, these methodologies have primarily focused on the mechanical structure of each statement, rather than the function that the statement may have on listeners' behavior. In accordance with political science literature and from the point of view of functional contextualism, political speeches function to influence the behavior

Ruth Anne Rehfeldt

schan@ego.thechicagoschool.edu

1 The Chicago School of Professional Psychology, 325 N. Wells St, Chicago, IL 60654, USA 
of members of a social community (e.g., party members, electorates, adversaries), acclaim the stances and virtues of the speaking party, undermine or "attack" the opposition, and defend against oppositional attacks (Belisle et al., 2018; Benoit et al., 1998, 2000; Knox \& Lucas, 2021). Therefore, verbal stimuli in these speeches have direct effects on such behavior. The relationship between verbal stimuli in speeches and their effect on social behavior is indicative of behavior in context, as the act of delivering a speech and its influence on social behavior are inseparable. Thus, a behavior-analytic evaluation of political speeches focuses on the function of verbal stimuli in speeches on listeners' behavior, which is markedly different from analyses conducted in other fields.

Behavior-analytic conceptualizations of language and verbal stimuli can be especially useful for analyzing the function of verbal stimuli, by which behavior analysts may predict and influence speeches or the behavior of the populace who contact the speeches. The prediction and influence of behavior are the goals of contextual behavioral science (Stewart et al., 2012). More importantly, political speeches are verbal behavior related to socially significant issues, as in speeches regarding international climate policies, laws, and presidential elections, and these issues are what behavior analysis aims to solve (Hayes et al., 2012; Skinner, 1953). Therefore, behavior analysts are in a more important position than ever to apply our scientific technology to complex cultural issues and contribute to the evolution of culturo-behavior science.

Planned government dissemination of verbal stimuli, broadcast through media, with the function of controlling the target responses of the populace, has been evident for decades and continues to proliferate. How exactly verbal stimuli in political speeches work to affect public behavior - especially when contingencies are remote or abstract, and when the public may never contact the consequences - can be clearly explained through relational frame theory (RFT; Törneke, 2010). Specifically, in contrast to Skinner's (1957) functional analysis of verbal behavior, which focuses on the influence of direct-acting contingencies (i.e., listener-mediating reinforcement of the speaker), RFT emphasizes the effects of indirect-acting contingencies - specifically, responding in accordance with relational frames. The three key features of arbitrarily applicable relational responding are mutual entailment, combinatorial entailment, and the transformation of stimulus function. Most important to this discussion is the transformation of stimulus function. This is because rules, as verbal stimuli that specify functional relations among events (Glenn, 1987), acquire different functions among individuals who contact them depending on their participation in relational frames. For example, an image of a burning globe may not initially function as an aversive stimulus to individuals with certain learning histories (e.g., were taught that global warming is not a threat but a science fiction, or that making profits and keeping jobs are more important) even though it represents how the earth will change if temperatures continue to increase. However, the visual depiction may transform to function as an aversive stimulus for such individuals if images of burning houses, loss of food, dying people, and so on are added. From the addition of the aversive relevant images, the observers may participate in relational framing (e.g., the images of burning houses, loss of food, or dying people are the same as "bad", they are the same as "global warming," and thus, through combinatorial entailment, global warming is the same as "bad"). Through this example, the same processes can be applied to the development of rules, their overall function, and how they influence behavior. 
Under the RFT framework, three types of rules are specified (see Törneke, 2010). Among them, the augmental, is the focus of our study, due to its important functions in political speeches. Hayes et al. (2001) defined an augmental as a rule that alters the reinforcing or punishing effects of specified consequences due to a relational network related to such consequences. More concretely, an augmental can enhance the reinforcing or punishing effects of a consequence not only by specifying a consequence that will be contacted but also by allowing the audience to "contact consequences that are abstract and can exert influence over behavior without even being contacted directly" (Törneke, 2010, p. 121). By altering the value of such consequences, an augmental may thus indirectly increase or decrease behavior. Numerous experimental studies have analyzed the effects that rules, especially augmentals, have on dimensions of behavior, such as online consumer purchasing behavior (Fagerstrom et al., 2010), patients' breast self-examination(Meyerowitz \& Chaiken, 1987), the identification of cancerous skin lesions (Critchfield \& Reed, 2016), exercise intensity (Jackson et al., 2016), and large-scale marketing in media on tobacco consumption among youths (Biglan et al., 2018). Based on the findings from previous studies, it is not surprising that augmentals are frequently used in political speeches that aim to change public behavior involved in abstract and remote contingencies.

Augmentals can be classified into two types: formative and motivative. A formative augmental establishes events as reinforcers or punishers, whereas a motivative augmental alters the momentary value of a previously established consequence. In addition, according to the direction of potential behavior change, augmentals can be further classified as reinforcer-establishing augmentals (REAs) and punisher-establishing augmentals (PEAs). An REA functions to establish the value of reinforcing or appetitive consequences and can be classified as a positive REA and a negative REA. On the other hand, a PEA functions to establish the value of punishing or aversive consequences and can be classified as a positive PEA and a negative PEA.

An augmental is formed through relational framing to acquire its functions or power. For instance, Barack Obama stated in his speech when entering the Paris Climate Agreement "that [entering the agreement]'s our most important mission, to make sure our kids and our grandkids have at least as beautiful a planet, and hopefully more beautiful, than the one that we have" (Obama, 2016, para. 11). This is an example of an REA, in which the reinforcing values of the otherwise not-so-relevant consequence of entering the agreement were enhanced (e.g., the populace's kids and grandkids would benefit from having a more beautiful planet). Here, the REA was formed through the frames of causality (e.g., ". . . to . .."), comparison (e.g., "most important mission," "more beautiful than"), and temporality (e.g., future and now) to acquire its functions of achieving public support for entering the agreement. In another example, Donald Trump stated in his speech aimed at withdrawing from the Paris Climate Agreement, "The Paris Accord would undermine our economy, hamstring our workers, weaken our sovereignty, impose unacceptable legal risks, and put us at a permanent disadvantage to the other countries of the world" (Trump, 2017, para. 60). Conversely, this is an example of a PEA, in which the punishing effects of the remote consequence of staying in the agreement were enhanced (e.g., undermining the economy, hamstringing workers, weakening sovereignty, imposing legal risks, and resulting in permanent disadvantage). Here, the PEA was formed through the frames of causality (e.g., ". . . would ..."), coordination (e.g., "undermine our economy," "hamstring our workers," 
or "impose unacceptable legal risks" is the same as "disadvantage"), and distinction (e.g., "disadvantage to the other") to achieve public support for exiting the agreement.

From the aforementioned examples, it is apparent that augmentals are a doubleedged sword that can be used either for political purposes in the form of propaganda to control public opinions and attitudes or for the phylogenic well-being of the citizenry in the form of specified long-term ultimate contingencies (Baum, 1995). Leigland (2005) suggested that the cultural values of a society are developed in the form of augmentals that specify ultimate contingencies. Thus, augmentals in political speeches, especially the formative type, can establish cultural values and thus indirectly lead to cultural practices. Today, cultural values surrounding the Paris Climate Agreement have been established, at least partly, through augmentals in presidential public speeches. These values will indirectly lead to cultural practices that protect or harm our environment and the long-term prosperity of humanity.

In the literature, a functional approach to content analysis in media sources, such as political speeches, was used by Shoemaker and Reese (1991), in which the authors grouped media content into functional categories and assessed the effects they produced. Though not behavior analytic, the practice fits well with the behavioral approach to understanding public behavior in relation to media content. Following this strategy, Rakos (1993) used a functional approach to content analysis regarding propaganda found in The New York Times during the periods preceding and during the first Iraq War. Specifically, Rakos conducted a behavior-analytic model of functional content analysis. The author operationally defined propaganda as a stimulus function in which antecedent stimuli are intended to evoke target operant responses of the individuals who encompass the citizenry (Rakos, 1993). In the study, four types of antecedent verbal stimuli were examined, including establishing operations, rules, symbols, and discriminative stimuli. Each category of verbal stimuli was delivered systematically in the media by the George H. W. Bush administration with the function to change public opinion toward defending Kuwait and opposing Iraq. The verbal stimuli systematically emitted by the Bush administration functioned as propaganda (Rakos, 1993). Consequently, changes in public opinion allowed the Bush administration to carry out a military defense of Kuwait and its economically important supply of oil. Rakos's study was the first to analyze political speeches surrounding an important social issue (e.g., war) using functional content analysis. Studies such as this one help to apply behavioral sciences to complex cultural issues affecting people and society and contribute to the further development of a culturo-behavior science. More specifically, it also helps behavior analysts understand how the verbal behavior of politicians affects public behavior.

Similar to the work of Rakos (1993), the current study focused on analyzing political speeches around climate change and global warming delivered by former presidents Obama and Trump, as climate change is also an important social issue that behavior analysts seek to address. Public debates on the balance between energy use and environmental protection continue to intensify as the effects of climate change worsen. According to the UN Environment Programme (n.d.-a), 2019 was the second hottest year on record, and global temperatures were $1.1{ }^{\circ} \mathrm{C}$ above preindustrial levels. This global change in temperature threatens worldwide economies and food sources and is caused by the human emission of greenhouse gasses, largely the product of the burning of fossil fuels (UN Environment Programme, n.d.-a). In 2016, under the Paris Climate 
Agreement, 125 parties ratified an attempt to limit the warming of the planet to 1.5-2 ${ }^{\circ} \mathrm{C}$ above preindustrial levels. Each nation voluntarily approved initiatives to lower greenhouse gas emissions in order to achieve this outcome (United Nations Climate Change, n.d.-a). These individualized initiatives were termed "nationally determined contributions" and included countrywide goals to combat climate change (United Nations Climate Change, n.d.-a, para. 1). The Paris Climate Agreement required that countries frequently report on emissions and implementation efforts, including a "global stocktake" occurring every 5 years to assess worldwide progress in essential areas (United Nations Climate Change, n.d.-b, para. 1). These areas included, but were not limited to, limiting global temperature increases, reducing greenhouse gas emissions, increasing climate change education and public awareness efforts, improving the transparency of emissions data, obligating developed nations to assist developing nations in fighting climate change, minimizing loss and damage from climate change-induced events, and enhancing frameworks using market and nonmarket mechanisms to reach these goals (United Nations Climate Change, n.d.-b). Also of note, the Green Climate Fund was developed in 2010 through the UN Framework Convention on Climate Change. As many as 194 countries approved the agreement and pledged to raise funds and investments in "low-emission climate resilient development" (UN Environment Programme, n.d.-b, para. 2). By 2020, \$5,600,000,000 had been raised internationally through the Green Climate Fund (UN Environment Programme, n.d.-b). In addition, thousands of scientists and hundreds of governments around the world have declared states of climate emergency (Calma, 2019).

Following these international agreements, former presidents Obama and Trump held separate approaches to the issue of climate change and delivered public speeches, broadcast through the news media, intended to evoke pro-Paris climate deal behavior and anti-Paris climate deal behavior from the citizenry, respectively. As in Rakos's (1993) study, these speeches could be considered propaganda too, in which a government exerts control over the opinions and attitudes of the citizenry by direct manipulation of significant symbols, stories, rumors, reports, pictures, and other forms of social communication (see Lasswell, 1927, for more). Propaganda is especially apparent when disseminated information is biased or not beneficial to the well-being of the citizenry in the long run. In fact, Biglan (2020) suggested that withdrawing from the Paris Climate Agreement would ultimately harm billions of people. So, regarding the issue of climate change, behavior analysts are in a vital position to analyze potential instances of propaganda used by government representatives aiming to "spread particular doctrines" (Rakos, 1993, p. 35), and to aid the citizenry in their ability to discriminate the functions of these speeches and make thoughtful decisions. Thus, by analyzing the functions of verbal stimuli (e.g., speeches), our hope is to provide guidance on media communication that leads to effective actions to reduce greenhouse gas emissions and slow down the climate change process.

The good news is that humans can plan ahead to avoid disaster (Biglan, 2020). Working with governments on the creation of public policy was beyond the scope of the study, but by analyzing how augmentals function in media content and political rhetoric, we may begin to guide decision making within the populace. Additionally, this analysis may also help us to effectively plan and use augmentals in establishing cultural values related to remote and abstract contingencies, and thus indirectly affect cultural practices and public behavior that will slow down the climate change process. 
In fact, Hayes et al. (1986), following an experimental analysis, concluded that rules, especially augmentals, could override or modify control of directly contacted contingencies. Therefore, following Rakos's (1993) functional content analysis of propaganda functioning to control the behavior of the populace during the first Iraq War, we conducted a functional content analysis on two speeches by different former U.S. presidents on the merits of entering or exiting the Paris Climate Agreement, with a new procedure using RFT, a post-Skinnerian analysis of verbal behavior.

The purposes of the current study were to (a) examine the effects of different types of augmentals (REA and PEA) and the ratio of their usage in media content on behavior change in the populace, (b) explore whether certain types of relational frames that formed augmentals were used more often and were more effective in achieving particular power or effects, and (c) provide guidance to the public on discriminating propaganda in media sources, thus potentially shifting behavior away from the functional intent of "spreading particular doctrines" (Rakos, 1993, p. 35). We tried to answer the following questions from the study:

1. Did REAs or PEAs have different effects on changing public behavior?

2. Were certain types of relational frames used more often to form REAs or PEAs?

3. What suggestions can we provide the public to help them discriminate propaganda in political speeches and make thoughtful decisions?

\section{Method}

\section{Source}

Two U.S. presidential speeches debating the merits of entering or exiting the Paris Climate Agreement were analyzed in the current study. The first speech was delivered by Barack Obama on October 5, 2016, approximately one month after the United States joined the Paris Climate Agreement. The speech was delivered in the Rose Garden of the White House. The speech was obtained through a White House government archival website (Obama, 2016). The second speech was delivered by Donald J. Trump on July 1, 2017, approximately one month after the United States withdrew from the Paris Climate Agreement. Again, the speech was delivered in the Rose Garden of the White House. The document was obtained from a White House government website (Trump, 2017).

Results of four survey reports conducted by researchers at the Yale Program on Climate Change Communication on Americans' opinions of staying or withdrawing from the agreement were also included in the study. The first survey, conducted in December 2015, was used as baseline (Leiserowitz et al., 2015); the next occurred in December 2016 (Leiserowitz et al., 2016) after Obama's speech; the third survey was completed in December 2017 (Leiserowitz et al., 2017) after Trump's speech; and the last was in April 2020 (Leiserowitz et al., 2020) before the 2020 presidential election. Results of the four surveys were compared to examine the functional relationship between the verbal stimuli used in each presidential speech and the behavior change of the public. 
Procedure The Obama and Trump speeches were first read, coded, and then analyzed by the first and second authors (Chan \& Katz) who were doctoral students in applied behavior analysis at a midwestern university. Each student was a Board Certified Behavior Analyst (BCBA). Response measurement took place in an online setting using GoToMeeting (https://www.goto.com/meeting) virtual conference software. Each speech was broken into sentences. Based on the specific reinforcers or punishers that were being described, each sentence itself or adjacent sentences were categorized into one of two types of augmentals: REAs or PEAs. As a result, each REA and PEA ranged from one to five sentences in length. Key words and phrases in the sentence(s) that were indicative of augmentals were highlighted in yellow. Words within the speeches that did not function as augmentals remained in plain black lettering.

Table 1 Definitions of Relational Frames Used in the Two Speeches and Corresponding Relational Contextual Cues

\begin{tabular}{|c|c|c|}
\hline Relational frames & Definitions & Relational contextual cues \\
\hline Coordination & $\begin{array}{l}\text { "The relation is one of identity, sameness, or } \\
\text { similarity: this is (or is similar to) that." } \\
\text { (Hayes et al., 2001, p. 35) }\end{array}$ & $\begin{array}{l}\text { Is; are; the same as; similar; } \\
\text { equals; like }\end{array}$ \\
\hline Opposition & $\begin{array}{l}\text { Involves comparisons that oppose or contradict } \\
\text { one another along some arbitrary or specific } \\
\text { dimensions (Hayes et al., 2001) }\end{array}$ & Is opposite of; inverse \\
\hline Distinction & $\begin{array}{l}\text { Encompasses arbitrarily behaving toward a } \\
\text { stimulus in terms of its disparities compared to } \\
\text { another stimulus or event, but "the nature of } \\
\text { an appropriate response is typically not } \\
\text { specified" (Hayes et al., 2001, p. 36) }\end{array}$ & $\begin{array}{l}\text { Not; different; unlike; dissimilar; } \\
\text { do not }\end{array}$ \\
\hline Comparison & $\begin{array}{l}\text { Includes a comparison of one event or stimulus } \\
\text { to another quantitatively or qualitatively along } \\
\text { a particular dimension (Hayes et al., 2001) }\end{array}$ & $\begin{array}{l}\text { Bigger; smaller; faster; slower; } \\
\text { better; worse; twice as fast as }\end{array}$ \\
\hline Hierarchical & $\begin{array}{l}\text { Includes a comparison of stimuli in which "A is } \\
\text { an attribute or member of B" (Hayes et al., } \\
\text { 2001, p. 37) }\end{array}$ & $\begin{array}{l}\text { Contains; is an attribute of; is a } \\
\text { member of; is a part of }\end{array}$ \\
\hline Temporal & $\begin{array}{l}\text { Another type of comparison in which abstract } \\
\text { comparisons are made between stimuli or } \\
\text { events along a temporal dimension of past, } \\
\text { present, and future (Hayes et al., 2001) }\end{array}$ & Before; prior to; after; later \\
\hline Spatial & $\begin{array}{l}\text { Entails the relative arrangement of objects in } \\
\text { space (Hayes et al., 2001, p. 38) }\end{array}$ & In-out; over-under; front-back \\
\hline Conditionality/causality & $\begin{array}{l}\text { "Events are said to cause events based on many } \\
\text { features, sequences, contiguity, } \\
\text { manipulability, practical exigencies, cultural } \\
\text { beliefs, and so on." (Hayes et al., 2001, p 38) }\end{array}$ & $\begin{array}{l}\text { Cause; because; due to; lead to; } \\
\text { if . . then . . .; force; result in; } \\
\text { result of }\end{array}$ \\
\hline Deictic & $\begin{array}{l}\text { "Specif[ies] a relation in terms of the perspective } \\
\text { of the speaker such as left-right; I-you (and all } \\
\text { of its correlates, such as 'mine'); here-there; } \\
\text { and now-then" (Hayes et al., 2001, p. 38) }\end{array}$ & $\begin{array}{l}\text { Left-right; I-you; here-there; } \\
\text { now-then }\end{array}$ \\
\hline
\end{tabular}


Further, within each augmental, the different types of relational frames used were coded based on the definitions of each type of relation from Relational Frame Theory: A Post-Skinnerian Account of Language and Cognition(Hayes et al., 2001). The frames used in the two speeches and their definitions are listed in Table 1. The contextual relation of each frame was written in blue lettering after each REA and in red lettering after each PEA on the speech documents. Relations that contained stimulus A, stimulus $\mathrm{B}$, and the contextual relational cue were counted, regardless of whether these stimuli were explicitly stated or implied, due to the clear purpose of the speeches for the listeners. Also, if there was more than one certain type of relation within each sentence, the frequency of that relation was counted.

After coding, the total number of each type of augmental was divided by the total number of augmentals in each speech, and then multiplied by 100 to determine a percentage of REAs and PEAs used by each former president. Similarly, the percentages of each type of relation demonstrated in both speeches were also calculated. Due to the fact that Trump's speech was almost four times as long as Obama's speech, and to ensure that the length of the speech did not affect our overall analysis, we converted the data to percentage values for a more accurate comparison. Finally, the results of the survey reports on Americans' opinions of supporting the agreement and not opposing to exit the agreement before Obama's speech, after Obama's speech, and after Trump's speech were compared.

\section{Interobserver Agreement (IOA)}

When the initial analysis and coding of the speeches were completed, definitions of REAs and PEAs, as well as the two speeches with highlighted augmentals, were shared with the third author (Schmidt) who performed IOA data collection on the type (i.e., REA or PEA) of each highlighted augmental. The third author was also a doctoral student in applied behavior analysis at a midwestern university and a BCBA. Results from the initial coding and analysis were not shared with the third author prior to data collection. IOA was conducted on 58\% of the augmentals in Obama's speech and 54\% in Trump's speech. A point-by-point IOA procedure was used in which the number of agreements of the readers on specific augmental incidences was divided by the number of agreements plus disagreements and multiplied by 100 to form a percentage (Kazdin, 2011). As a result, IOA on augmentals was $92.9 \%$ for Obama’s speech and $92.7 \%$ for Trump's speech.

\section{Results}

\section{Obama's Speech}

\section{Types of Augmentals}

Obama's speech was only one fourth of the length of Trump's. A total of 23 REAs were counted in his speech. Twenty of them were positive REAs, whereas only three were negative REAs. Obama only engaged in one positive PEA and did not use any negative PEAs at all (see Figs. 1 and 2). 


\section{Types of Frames}

In terms of the frames used in Obama's augmentals $(M=29.03 \%$ causal or comparison frames), both causal and comparison frames each occupied $29.03 \%$ of the total frames, and the temporal frame occupied $19.35 \%$, representing a major part of his speech. Other frames used were the deictic $(9.68 \%)$, hierarchy $(4.84 \%)$, distinction $(4.84 \%)$, coordination (1.61\%), and spatial (1.61\%) frames (see Fig. 3).

\section{Trump's Speech}

\section{Types of Augmentals}

Trump engaged in a total of 49 REAs, which represented $49 \%$ of the total augmentals in his speech. Among them, 37 were positive REAs, and 12 were negative REAs, which represented $27 \%$ and $12 \%$ of the total augmentals, respectively. However, he emitted 51 PEAs, which represented $51 \%$ of the total augmentals throughout his speech. These included 23 positive PEAs and 29 negative PEAs, representing 23\% and $29 \%$ of the total number of augmentals, respectively (see Figures 1 and 2).

\section{Types of Frames}

Among the frames used within Trump's augmentals $(M=30.41 \%$ coordination frames), the majority of them were the coordination $(30.41 \%)$ and causality $(27.03 \%)$ frames. Then, from most to least, the other frames included comparison $(16.89 \%)$, distinction $(13.51 \%)$, deictic $(12.84 \%)$, temporality $(5.41 \%)$, hierarchy $(4.05 \%)$, and opposition (2.70\%; see Figure 4).

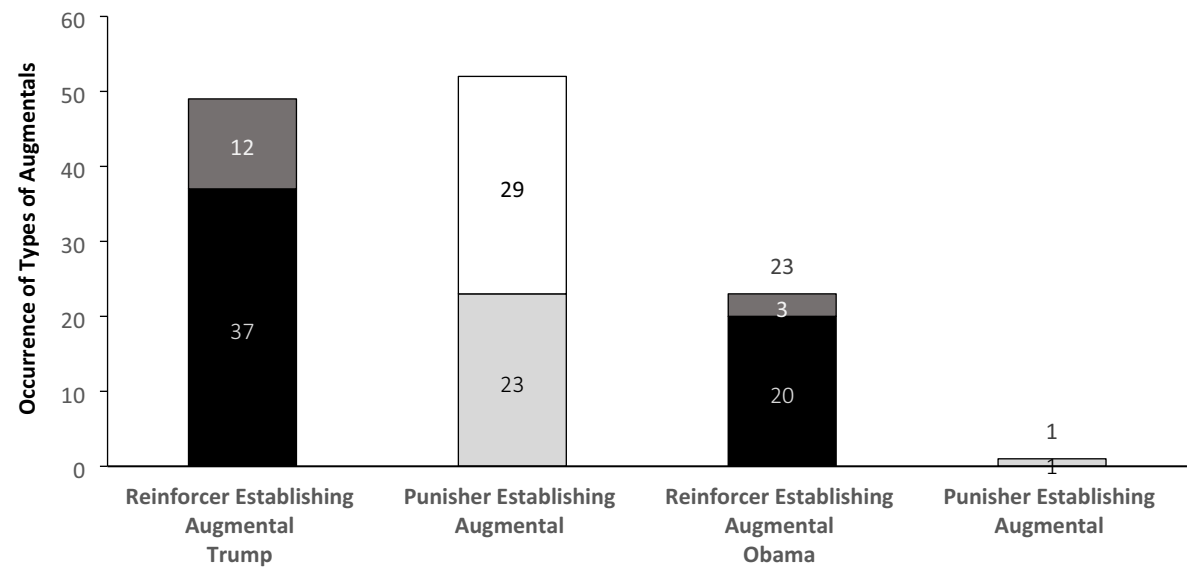

$$
\begin{array}{|l}
\hline \text { Positive Reinforcer Establishing Augmental } \quad \square \text { Negative Reinforcer Establishing Augmenta } \\
\square \text { Positive Punisher Establishing Augmental } \quad \square \text { Negative Punisher Establishing Augmental }
\end{array}
$$

Fig. 1 Occurrences of Reinforcer-Establishing Augmentals and Punisher-Establishing Augmentals Used in the Two Presidential Speeches 


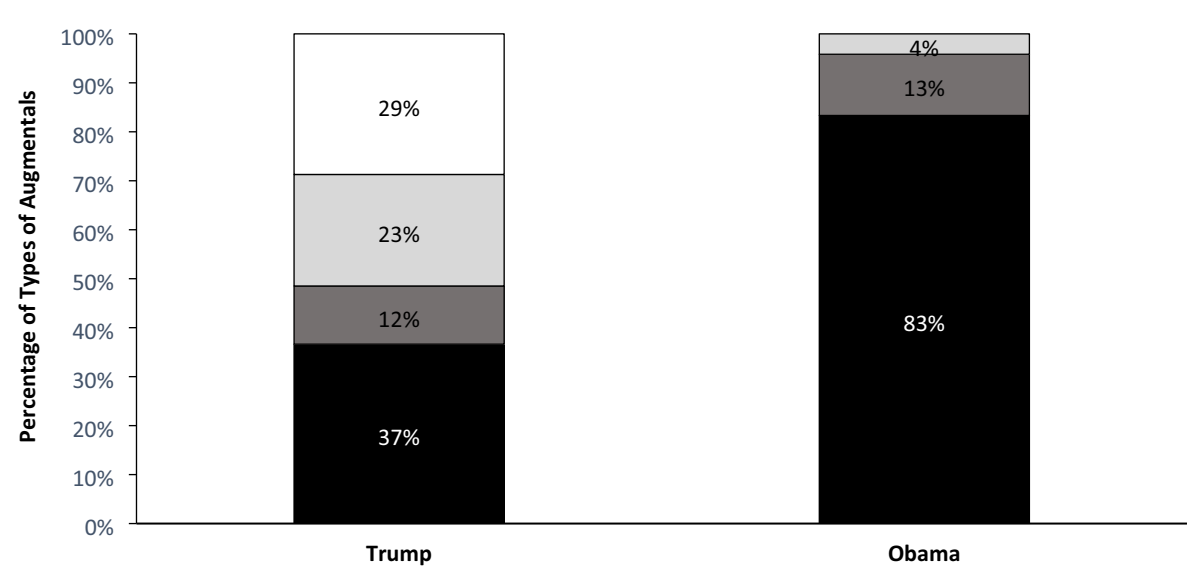

— Positive Reinforcer Establishing Augmental $\square$ Negative Reinforcer Establishing Augmental

$\square$ Positive Punisher Establishing Augmental $\quad \square$ Negative Punisher Establishing Augmental

Fig. 2 Percentage of Reinforcer-Establishing Augmentals and Punisher-Establishing Augmentals Used in the Two Presidential Speeches

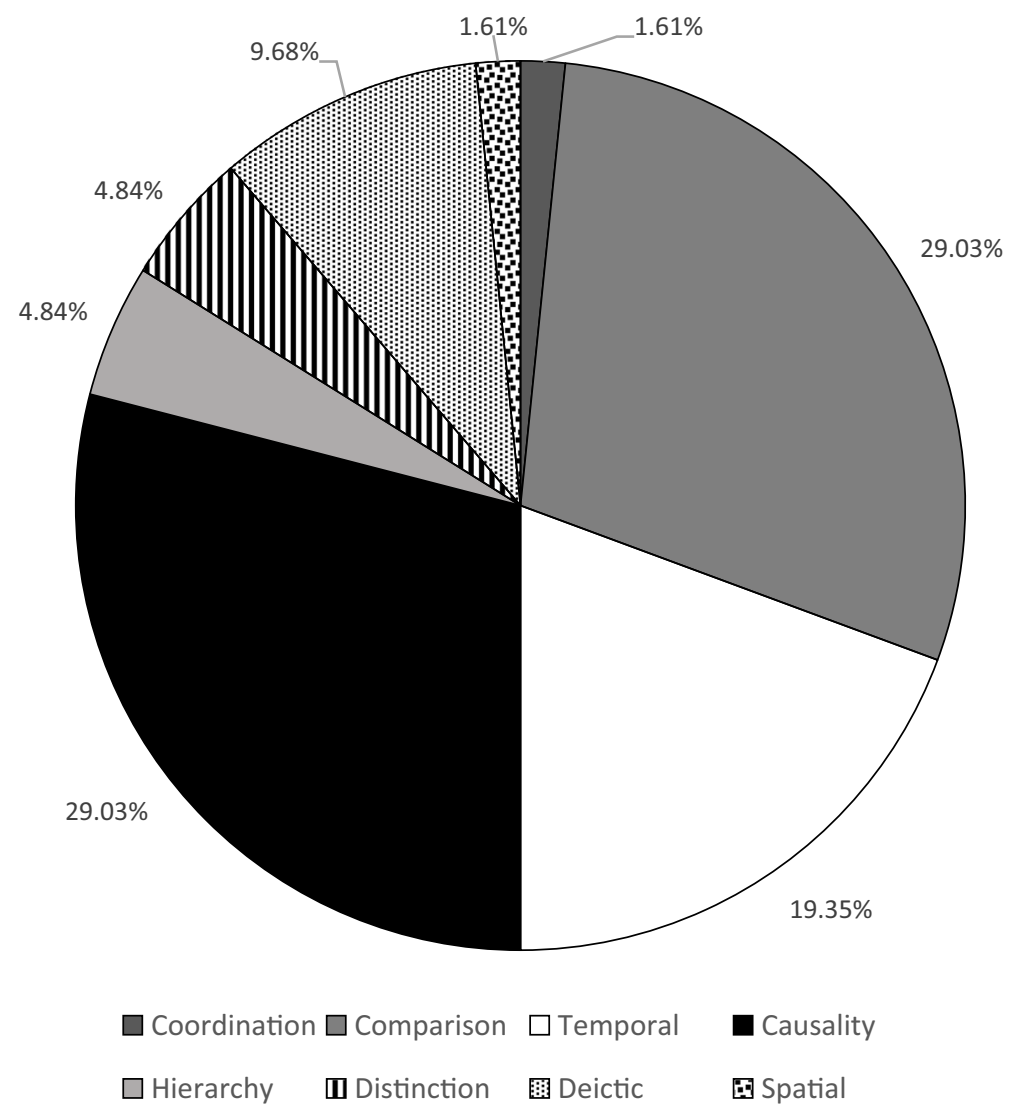

Fig. 3 Percentage of Types of Frames Used in Obama's Speech 


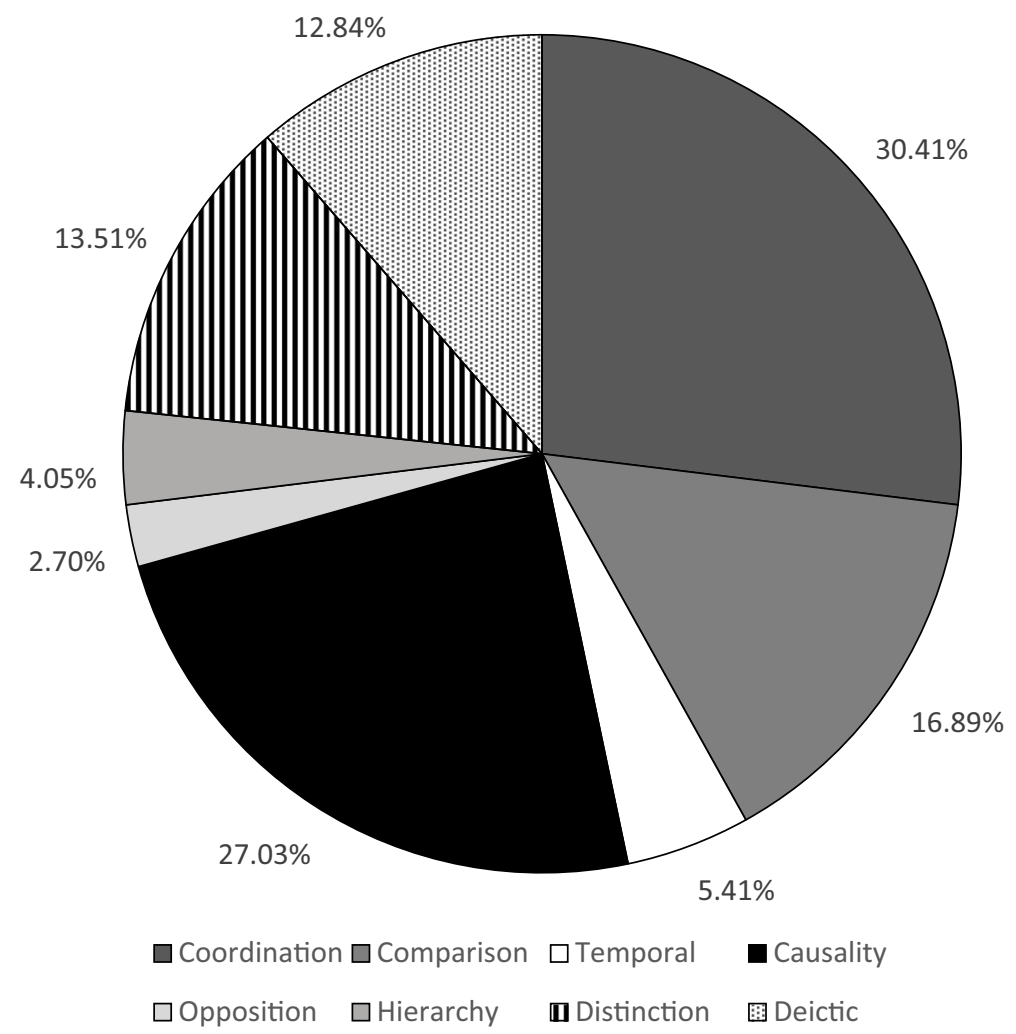

Fig. 4 Percentage of Types of Frames Used in Trump's Speech

\section{Americans' Opinions on Staying in or Withdrawing From the Paris Climate Agreement}

According to the survey results from the Yale Program on Climate Change Communication, prior to Obama's speech in October 2015, 79\% of Democrats, $62 \%$ of Independents, and only $46 \%$ of Republicans supported an agreement in Paris (Leiserowitz et al., 2015). In November 2016, after Obama's speech, more respondents supported the decision of participating in the agreement, as evidenced by $86 \%$ of Democrats, $61 \%$ of Independents, and $51 \%$ of Republicans supporting the decision. Only conservative Republicans showed divided opinions within their party (Leiserowitz et al., 2016). After Trump's speech, in October 2017, a further increase in support of the agreement occurred; 94\% of Democrats, $67 \%$ of Independents, and $56 \%$ of Republicans supported U.S. participation in the agreement (Leiserowitz et al., 2017). Finally, by April 2020, prior to the 2020 presidential election, 94\% of Democrats, $76 \%$ of Independents, and 58\% of Republicans expressed support for participating in the agreement, showing bipartisan support (Leiserowitz et al., 2020; see Table 2 and Figure 5).

Conversely, according to the same surveys, in November 2016, when the United States had recently entered the Paris Climate Agreement, only $14 \%$ of Democrats, $38 \%$ 
Table 2 Americans Across Party Lines Who Support the Agreement in 2015, 2016, 2017, and 2020 and Who Do Not Support the Agreement in 2016 and Do Not Oppose Trump's Decision to Pull Out of the Agreement in 2017 and 2020

\begin{tabular}{llllll}
\hline Sentiment & Affiliation & Baseline & $\begin{array}{l}\text { Post-Obama } \\
\text { speech }\end{array}$ & $\begin{array}{l}\text { Post-Trump } \\
\text { speech }\end{array}$ & $\begin{array}{l}\text { Probe } \\
\text { in 2020 }\end{array}$ \\
\hline Support the agreement & Democrat & 79 & 86 & 94 & 94 \\
& Independent & 62 & 61 & 67 & 76 \\
& Republican & 46 & 51 & 56 & 58 \\
Do not support the agreement & Democrat & 14 & 15 & 7 \\
and do not oppose exiting the agreement & Independent & 38 & 42 & 34 \\
& Republican & 48 & 62 & 69 \\
\hline
\end{tabular}

Note. This table was developed based on the results of four survey reports from the Yale Program on Climate Change Communication on Americans' opinions of staying in or withdrawing from the agreement (Leiserowitz et al., 2015, 2016, 2017, 2020). Americans' opinions on staying in or exiting the agreement were not collected in 2015 because the agreement took effect in November 2016.

of Independents, and $48 \%$ of Republicans did not support entering the agreement. In October 2017, after Trump's speech, an increase also occurred among this group; 15\% of Democrats, $42 \%$ of Independents, and $62 \%$ of Republicans did not oppose Trump's decision to exit the agreement. In April 2020, the percentages decreased to 7\% of Democrats and $34 \%$ of Independents, but increased to $69 \%$ of Republicans, showing a huge gap between the two parties (see Table 2 and Figure 5).

\section{Discussion}

\section{Analysis of the Findings}

Based on the results of the content analysis of the two speeches, both former presidents used augmentals differently in their speeches and aimed to affect public opinions, values, and actions toward the Paris Climate Agreement. The most pertinent difference was that Obama used almost solely REAs, whereas Trump engaged in equal ratios of REAs and PEAs. Also, Trump's speech consisted of over four times as many augmentals as Obama's, which likely created more motivation to exit the agreement (Hayes et al., 2001; Shoemaker \& Reese, 1991). By using primarily REAs, Obama emphasized the reinforcing effect of entering the Paris Climate Agreement. By using a combination of roughly equal numbers of REAs and PEAs, Trump not only successfully established the punishing effect of entering the agreement but also established the reinforcing effect of exiting it. In order to transform a previously established cultural value - that entering the Paris Climate Agreement is crucial—both REAs and PEAs for the opposite value were equally employed and four times the effort was made. Because PEAs enhanced the punishing effects of entering the agreement through relational networks, such verbal rules made participating in the agreement aversive and thus evoked strong emotional and behavioral responses to avoid the aversive stimuli. Due to this punishment effect, PEAs are likely to be more effective than REAs 
Obama Speech Trump Speech

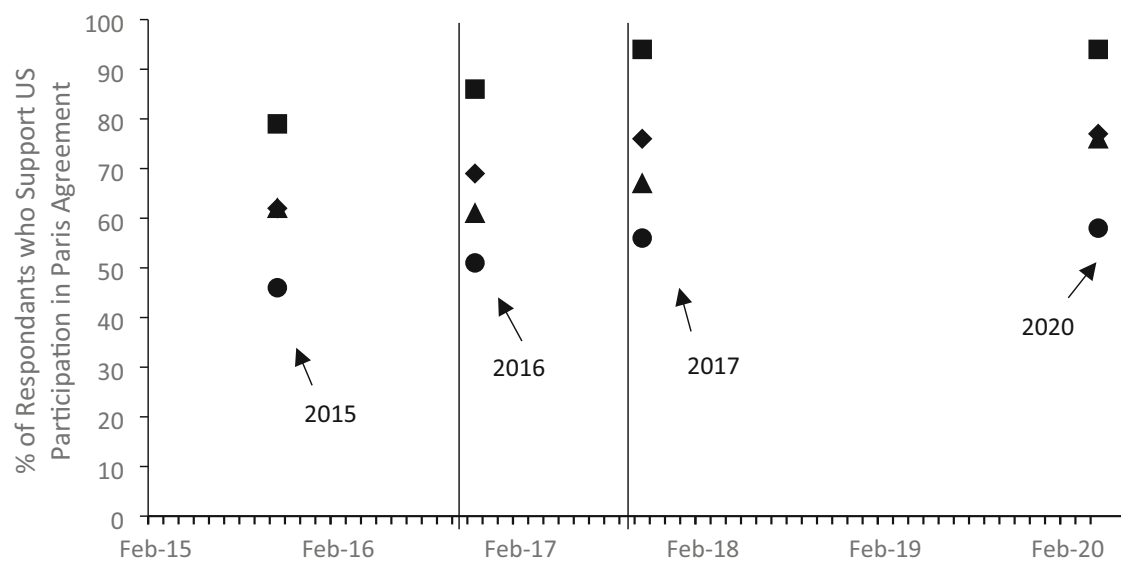

Democrats Percentage

Independents Percentage

Republicans Percentage

Total Percentage

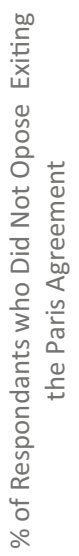

Obama Speech Trump Speech

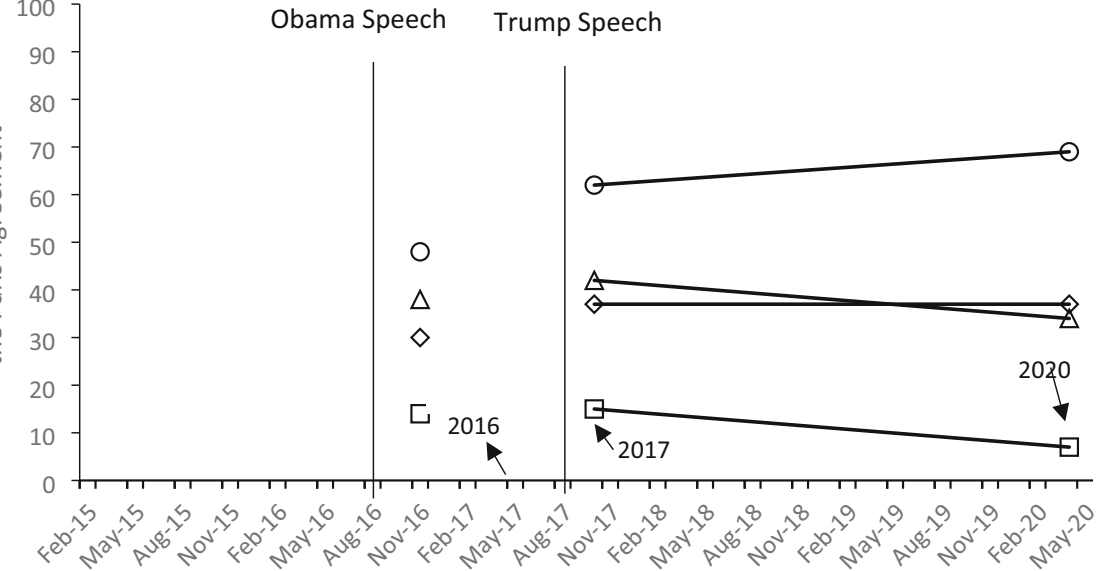

$\square$ Democrats Percentage

$\Delta$ Independent Percentage

O Republicans Percentage

$\diamond$ Total Percentage

Fig. 5 Americans Across Party Lines Who Support the Agreements in 2015, 2016, 2017, and 2020 (Top Panel) and Who Do Not Support the Agreement in 2016 and Do Not Oppose Trump's Decision to Pull Out of the Agreement in 2017 and 2020 (Bottom Panel). Note. These graphs were developed based on the results of four survey reports from the Yale Program on Climate Change Communication on Americans' opinion of staying in or withdrawing from the agreement (Leiserowitz et al., 2015, 2016, 2017, 2020). Americans' opinions of staying in or exiting the agreement were not collected in 2015 because the agreement took effect in November 2016.

in changing public behavior in the short term. This case study on political rhetoric is an exemplar of the use of augmentals in propaganda. By using augmentals, political leaders present verbal stimuli that influence the probability of specific behaviors of support among the public because of the relational functions of those stimuli. By manipulating augmentals in political speeches, in terms of the type (i.e., REA or PEA), number, and proportion between them, political leaders thus can form or 
transform cultural values of verbal communities in their desired direction, and thereby shift the covert and overt behavior of the populace accordingly.

In terms of the use of different categories of relational frames in these augmentals, Obama focused on the frames of causality, comparison, and temporal relations to create REAs for specific reasons: (a) to establish the contingency that by entering the agreement, the populace's children would be free from damage due to climate change in the future; and (b) to establish the differences between the results of being "in" and "out" of the agreement. These augmentals, in turn, aimed to affect public behavior (e.g., opinions, values, and actions; Fagerstrom et al., 2010). On the contrary, Trump tended to use frames of coordination, causality, comparison, distinction, and deictic relations to create REAs and PEAs for specific reasons: (a) to establish the sameness among entering the agreement, losing money, losing jobs, closing businesses, and harming the economy; (b) to establish the sameness among exiting the agreement, increasing jobs, growing businesses, growing the economy, and following his leadership; and (c) to establish significant differences between the results of being "in" and "out" of the agreement. Again, these augmentals aimed to affect the public behavior of the citizenry. From this analysis, it seems that political leaders tend to use certain types of frames, such as causality, comparison, coordination, distinction, temporal, and deictic relations, more than others in their augmentals in political speeches. Specifically, the frames of coordination, causality, comparison, and distinction are used more intensively when political leaders try to change an existing cultural value. Because augmentals in political speeches, including REAs and PEAs, are usually established by connecting long-term, remote consequences with current actions, it is not surprising to see that the relational frames primarily involved deictic, causal, and coordination relations. In addition, political speeches tend to focus on acclaiming the stances and virtues of the speaking party, attacking the opposition, and defending against oppositional attacks (Benoit et al., 1998, 2000; Knox \& Lucas, 2021). Thus, relational frames such as comparison, distinction, and coordination can be expected to be used frequently.

However, based on the survey results of the Yale Program on Climate Change Communication, since 2015, there has been a steady ascending trend in the percentage of Americans who support an international agreement to combat global warming. It seems that public awareness and support for stopping climate change have gradually increased during the last few years, due in part to education, political speeches, and other forms of mass media. Generally, more Democrats expressed support for entering the Paris Climate Agreement than Independents. Republicans exhibited the least amount of support for an international agreement. The difference in support between Democrats and Republicans was consistent from 2015 to 2020 (see Table 2 and Figure 5).

What is perhaps most interesting from the results was the change in the percentage of respondents who did not support the agreement or did not oppose exiting the agreement. In fall 2017, immediately after Trump's speech, there was a general increase in the percentage of those respondents who did not oppose exiting the agreement compared with those who did not support the agreement in the previous year across Democrats (from 14\% to 15\%), Independents (from 38\% to 42\%), and Republicans (from $48 \%$ to $62 \%$; see Table 2 and Figure 5). Moreover, based on the overlapping data (see the column labeled Post-Trump Speech in Table 2), an increased number of respondents expressed the importance of participating in the Paris 
agreement, but at the same time also expressed that they did not oppose Trump's decision to pull out of the agreement. Such conflicting opinions among this small group of respondents across parties were likely the results of Trump's propaganda that emphasized short-term effects while ignoring long-term consequences. However, these respondents only represented a small number and did not affect the general trend of supporting the agreement. In April 2020, the percentage of Republican respondents who did not oppose exiting the Paris Accord increased further, whereas the level dropped back among Democrats and Independents. This indicated that the effect of propaganda could be short-lived for some groups in verbal communities who could freely access information and were exposed to different contingencies in the larger culture.

From the social psychology perspective, the change in voters' opinions following the presidential speeches may be explained by the interaction of primacy and recency effects. The primacy effect refers to the tendency to place disproportionate salience on initial information because of a cognitive bias, whereas the recency effect refers to the tendency to remember the information that is presented most recently because it may be more available in short-term memory (Panagopoulos, 2011). Both have been applied to political messaging and persuasion. Indeed, the experimental literature in social psychology has found that the timing of political messages plays an important role in evoking public actions (Nickerson, 2007; Panagopoulos, 2011). In the current study, right after Obama's speech in 2016, the percentage of Americans who supported the Paris Climate Agreement increased; right after Trump's speech in 2017, the percentage of Americans who did not oppose Trump's decision to exit the agreement also increased. The change of opinion seemed to result from the recency effect of the most recent information (i.e., the latest presidential speech). Conversely, after Trump's speech in 2017, the general trend of Americans supporting the agreement still increased, rather than decreased, which might be related to the primacy effect of the initial information (i.e., Obama's speech). These findings suggest that, in addition to the frequency mentioned previously, the timing of political augmentals may also play an important role.

Further, the ways in which augmentals in political speeches form social values and affect public behaviors are best analyzed within the paradigm of cultural selection. Culture is an interlocking set of social contingencies maintained by a group (Mattaini, 1995; Skinner, 1953), and its practices are supported by cultural entities and selected by the aggregate outcome for the group, its members, or those who have power (Biglan, 1995). The selection of cultural practices related to entering or exiting the Paris Climate Agreement is likely determined by interactions of interlocking contingencies at multiple levels (Glenn et al., 2016). So, in addition to the populace's behavior being affected by political rhetoric and propaganda, it is also likely influenced by a myriad of interlocking contingencies at the individual, group (e.g., school, workplace, party), and societal levels (e.g., scientific findings in mass media). See the interlocking practices of exiting the Paris Climate Agreement in American culture in Fig. 6.

\section{Limitations and Future Directions}

One limitation of this study falls on the IOA procedure. IOA was only conducted on categories of augmentals but not on the types of frames. Future studies may include 


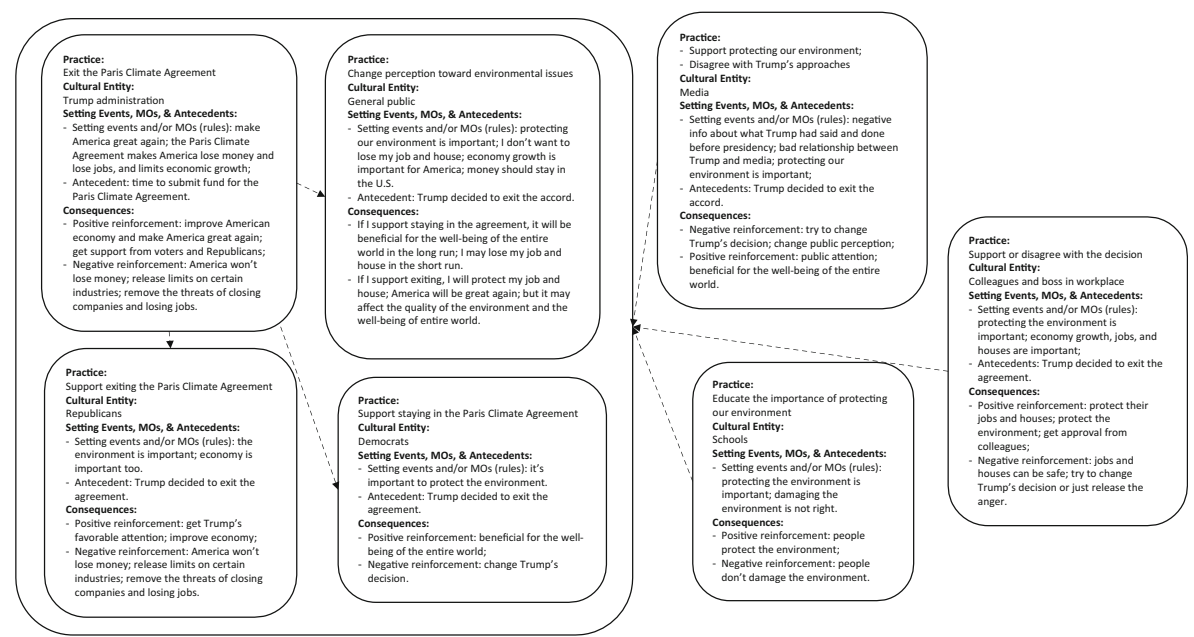

Fig. 6 Interlocking Practices of Exiting the Paris Climate Agreement in American Culture. Note. The above diagram was developed based on Mattaini (1996). MO = motivating operation

IOA on that area. Also, the effect of augmentals on behavior change was only examined based on public survey results, rather than the manipulation of experimental conditions and the direct observations of behavior change among participants before and after a political speech is delivered. Even if a functional relation was demonstrated in the study, future researchers may consider conducting a poll of participants before and after a political speech is delivered, and directly examining the effect of augmentals on covert and overt behavior change.

Further research on the effect that augmentals have on behavior change can be extended to several other domains in society. For example, a functional content analysis can be conducted on historical artifacts, public policy, and advertisements. Additionally, in some situations, it may be a methodological challenge to prove a functional relationship between public rhetoric and rates of behavior from the populace (e.g., historical artifacts), so continued efforts to develop procedures toward this aim will be worthwhile too. Last, researchers should further examine which type of augmental, REAs or PEAs, is most effective in promoting compliance with professional recommendations when providing feedback is impossible. For instance, if school teachers or parents do not follow professional recommendations in daily practices, behavior analysts would not have the opportunity to provide feedback on following or not following the recommendations at all.

\section{Final Thoughts}

In summary, an augmental, as a type of rule that alters the value of consequences, has a reinforcer-establishing effect or a punisher-establishing effect (Hayes et al., 2001). Augmentals can be used either in establishing cultural values that are beneficial for the populace (Leigland, 2005) or in publicizing political points of view to exert control on public opinions through propaganda (Rakos, 1993). In addition, studies have also shown the effect of augmentals on changing consumer behavior during online purchases (Fagerstrom et al., 2010), influencing smoking behavior among youths through 
tobacco marketing (Biglan et al., 2018), and affecting patients' self-examination behavior in health care settings (e.g., Critchfield \& Reed, 2016; Meyerowitz \& Chaiken, 1987).

The power of presidential augmentals can be seen in other verbal stimuli presented by Trump, through both rule omission (e.g., regarding mask wearing during the COVID-19 pandemic) and rule commission (e.g., regarding actions to rectify a stolen election in 2020). For instance, Trump wrote on his Twitter account on December 30, 2020, "The United States had more votes than it had people voting, by a lot. This travesty cannot be allowed to stand. It was a Rigged Election, one not even fit for third world countries!" (Trump, 2020, December 30). The verbal behavior within this single tweet forms a relational network in which the election is equated with "rigged" and "travesty" and is "not fit for third world countries." These PEAs might evoke actions from the populace (e.g., protests) and shift opinion away from trust in democratic elections. Likewise, in an example of rule omission, Trump, for months, did not engage in REAs regarding the effectiveness of masks despite evidence of their efficaciousness of slowing the spread of COVID-19(see Gandhi et al., 2020). For a time, Trump even refused to be photographed wearing a mask (Victor et al., 2020). The effect of this rule omission is unknown as few data exist on public adherence to mask-wearing recommendations.

Therefore, an augmental can be a powerful verbal tool. A question that behavior analysts can focus on is how to guide the citizenry toward recognizing the functional use of such augmentals. Furthermore, behavior analysts can wrestle with the question of how to offer guidance to public and private institutions so that such a powerful verbal tool can be used in a way that benefits the populace and fulfills long-term cultural values. However, behavior analysts should note that government should not use policy instruments without societal support (Tummers, 2019). Whether a public policy can really lead to effective behavior change and societal support depends not only on effectively using such verbal tools but also on considering the benefits and well-being of the citizenry and the long-term cultural values of the society.

Finally, the Trump administration ended shortly after it had begun the process to formally exit the Paris Climate Agreement in November 2020. President Joe Biden, on his 1st day in office, signed an executive order to rejoin the Paris Agreement and lead the world back on track in the fight against climate change (Frazin, 2021). In light of this apparent reversal of policy, how have citizens viewed the issue of being "in" or "out" of the Paris Climate Agreement in relation to their jobs and income in the short run, the well-being of their communities in the long run, and the quality of the environment that everyone is responsible for? Already, we believe we know the answers.

Authors' contributions All authors contributed to the study's conception and design. All authors read and approved the final manuscript.

Funding No funding was received for conducting this study.

Data availability The data sets generated during and/or analyzed during the current study are available from the corresponding author on reasonable request. 


\section{Declarations}

Conflicts of interest/competing interests The authors declare that they have no conflict of interest.

Code availability Not applicable.

\section{References}

Baum, W. M. (1995). Rules, culture, and fitness. The Behavior Analyst, 18(1), 1-21. https://doi.org/10.1007/ BF03392688

Belisle, J., Paliliunas, D., Dixon, M. R., \& Tarbox, J. (2018). Feasibility of contextual behavioral speech analyses of US presidents: Inaugural addresses of Bill Clinton, George W. Bush, Barack Obama, and Donald Trump, 1993-2017. Journal of Contextual Behavioral Science, 10, 14-18. https://doi.org/10. 1016/j.jcbs.2018.07.002

Benoit, W. L., Blaney, J. R., \& Pier, P. M. (1998). Campaign '96: A functional analysis of acclaiming, attacking, and defending. Praeger.

Benoit, W. L., Blaney, J. R., \& Pier, P. M. (2000). Acclaiming, attacking, and defending: A functional analysis of U.S. nominating convention keynote speeches. Political Communication, 17, 61-84.

Biglan, A. (1995). Changing cultural practices: A contextualist framework for intervention research. Context Press.

Biglan, A. (2020). Rebooting capitalism: How we can forge a society that works for everyone. Values to Action.

Biglan, A., Van Ryzling, M., \& Westling, E. (2018). A public health framework for the regulation of marketing. Journal of Public Health, 40, 66-75. https://doi.org/10.1057/s41271-018-0154-8

Brown, B. (2021). Trump Twitter archive. https://www.thetrumparchive.com/?searchbox=\%22rigged\% 2Belection\%22

Calma, J. (2019). 2019 was the year of "climate emergency" declarations. The Verge. https://www.theverge. com/2019/12/27/21038949/climate-change-2019-emergency-declaration

Charteris-Black, J. (2014). Analysing political speeches: Rhetoric, discourse and metaphor. Palgrave Macmillan.

Critchfield, T. S., \& Reed, D. D. (2016). Does hearing about cancer influence stimulus control? An exploratory study of verbal modulation of stimulus generalization. The Analysis of Verbal Behavior, $32(1), 46-59$.

Fagerstrom, A., Foxall, G. R., \& Arntzen, E. (2010). Implications of motivating operations for the functional analysis of consumer choice. Journal of Organizational Behavior Management, 30, 110-126.

Frazin, R. (2021). US officially rejoins Paris Climate Agreement. The Hill. https://thehill.com/policy/energyenvironment/539554-us-officially-rejoins-paris-agreement

Gandhi, M., Beyrer, C., \& Goosby, E. (2020). Masks do more than protect others during COVID-19: Reducing the inoculum of SARS-CoV-2 to protect the wearer. Journal of General Internal Medicine, 35(10), 3063-3066.

Glenn, S. S. (1987). Rules as environmental events. The Analysis of Verbal Behavior, 5, $29-32$.

Glenn, S. S., Malott, M. E., Andery, M. A. P. A., Benvenuti, M., Houmanfar, R. A., Sandaker, I., Todorov, J. C., Tourinho, E. Z., \& Vasconcelos, L. A. (2016). Toward consistent terminology in a behaviorist approach to cultural analysis. Behavior and Social Issues, 25, 11-27. https://doi.org/10.5210/bsi.v.25i0. 6634

Hayes, S. C., Barnes-Holmes, D. E., \& Roche, B. E. (2001). Relational frame theory: A post-Skinnerian account of human language and cognition. Springer.

Hayes, S. C., Barnes-Holmes, D., \& Wilson, K. G. (2012). Contextual behavioral science: Creating a science more adequate to the challenge of the human condition. Journal of Contextual Behavioral Science, 1(12), 1-16. https://doi.org/10.1016/j.jcbs.2012.09.004

Hayes, S. C., Brownstein, A. J., Zettle, R. D., Rosenfarb, I., \& Korn, Z. (1986). Rule-governed behavior and sensitivity to changing consequences of responding. Journal of the Experimental Analysis of Behavior, 45(3), 237-256. https://doi.org/10.1901/jeab.1986.45-237 
Jackson, M. L., Williams, W. L., Hayes, S. C., Humphreys, T., Gauthier, B., \& Westwood, R. (2016). Whatever gets your heart pumping: The impact of implicitly selected reinforcer-focused statements on exercise intensity. Journal of Contextual Behavioral Science, 5(1), 48-57. https://doi.org/10.1016/j.jcbs. 2015.11.002

Kazdin, A. E. (2011). Single-case research designs: Methods for clinical and applied settings (2nd ed.). Oxford University Press.

Knox, D., \& Lucas, C. (2021). A dynamic model of speech for the social sciences. American Political Science Review, 115, 649-666.

Lasswell, H. D. (1927). Propaganda technique in the World War. Ravenio Books.

Leigland, S. (2005). Variables of which values are a function. The Behavior Analyst, 28(2), 133-142.

Leiserowitz, A., Maibach, E., Rosenthal, S., Kotcher, J., Ballew, M., Bergquist, P., Gustafson, A., Goldberg, M., \& Wang, X. (2020). Politics and global warming, April 2020. Yale Program on Climate Change Communication. https:/climatecommunication.yale.edu/publications/politics-global-warming-april-2020/ 8/

Leiserowitz, A., Maibach, E., Roser-Renouf, C., Feinberg, G., \& Rosenthal, S. (2015). Politics and global warming, fall 2015. Yale Program on Climate Change Communication. https://climatecommunication. yale.edu/publications/voters-prefer-candidates-who-support-climate-friendly-policies/6/

Leiserowitz, A., Maibach, E., Roser-Renouf, C., Rosenthal, S., \& Cutler, M. (2016). Politics and global warming, November 2016. Yale Program on Climate Change Communication. https:// climatecommunication.yale.edu/wp-content/uploads/2016/12/Global-Warming-Policy-PoliticsNovember-2016.pdf

Leiserowitz, A., Maibach, E., Roser-Renouf, C., Rosenthal, S., Cutler, M., \& Kotcher, J. (2017). Politics and global warming, October 2017. Yale Program on Climate Change Communication. https:// climatecommunication.yale.edu/publications/politics-global-warming-october-2017/5/

Mattaini, M. A. (1995). Teaching cultural design: Shaping new behaviorists. Behavior and Social Issues, 5(2), 21-28. https://doi.org/10.5210/bsi.v5i2.220

Mattaini, M. A. (1996). Envisioning cultural practices. The Behavior Analyst, 19(2), 257-272. https://doi.org/ 10.1007/BF03393168

Meyerowitz, B. E., \& Chaiken, S. (1987). The effects of message framing on breast self-examination attitudes, intentions, and behavior. Journal of Personality and Social Psychology, 52(3), 500-510.

Nickerson, D. (2007). Quality is job one: Professional and volunteer voter mobilization calls. American Journal of Political Science, 51(2), 269-282.

Obama, B. (2016). Remarks by the president on the Paris Agreement. The White House: President Barack Obama. https://obamawhitehouse.archives.gov/the-press-office/2016/10/05/remarks-president-parisagreement

Panagopoulos, C. (2011). Timing is everything? Primacy and recency effects in voter mobilization campaigns. Political Behavior, 33(1), 79-93.

Rakos, R. F. (1993). Propaganda as stimulus control: The case of the Iraqi invasion of Kuwait. Behavior and Social Issues, 3(1-2), 35-62.

Shoemaker, P. J., \& Reese, S. D. (1991). Mediating the message: Theories of influences on mass media content. Routledge; Longman.

Skinner, B. F. (1953). Science and human behavior. Macmillan.

Skinner, B. F. (1957). Verbal behavior. Copley Publishing Group.

Skinner, B. F. (1981). Selection by consequences. Science, 213(4507), 501-504.

Stewart, I., Villatte, J., \& McHugh, L. (2012). Approaches to the self. In L. McHugh \& I. Stewart (Eds.), The self and perspective taking: Contributions and applications from modern behavioral science (pp. 3-35). Context Press.

Törneke, N. (2010). Learning RFT: An introduction to relational frame theory and its clinical applications. Context Press; New Harbinger Publications.

Trump, D. (2017). Statement by President Trump on the Paris Climate Accord. The White House. https:// www.whitehouse.gov/briefings-statements/statement-president-trump-paris-climate-accord/

Trump. D. [@DonaldTrump]. (2020). The United States had more votes than it had people voting, by a lot. This travesty cannot be allowed to [Tweet]. Twitter. https://www.thetrumparchive.com/?searchbox=\% $22 \mathrm{The}+$ United+States+had+more+votes+than+it+had+people+voting $\% 2 \mathrm{C}+\mathrm{by}+\mathrm{a}+$ lot.+This+travesty+ cannot+be+allowed+to+stand.+It+was+a+Rigged+Election $\% 2 \mathrm{C}+$ one+not+even+fit+for+third+world+ countries $\% 21 \% 22$ 
Tummers, L. (2019). Public policy and behavior change. Public Administration Review, 79, 925-930.

UN Environment Programme. (n.d.-a). Facts about the climate emergency. Retrieved September 17, 2020, from https://www.unenvironment.org/explore-topics/climate-change/facts-about-climate-emergency

UN Environment Programme. (n.d.-b). Green climate fund. Retrieved September 17, 2020, from https://www. unenvironment.org/about-un-environment/funding-and-partnerships/green-climate-fund

United Nations Climate Change. (n.d.-a). Nationally determined contributions (NDCs). Retrieved from https:// unfccc.int/nationally-determined-contributions-ndcs\#eq-3

United Nations Climate Change. (n.d.-b). Global stocktake. Retrieved September 1, 2021, from https://unfccc. int/topics/science/workstreams/global-stocktake

Victor, D., Serviss, L., \& Paybarah, A. (2020). In his own words, Trump on the coronavirus and masks. The New York Times. https:/www.nytimes.com/2020/10/02/us/politics/donald-trump-masks.html 